\title{
LGBT Inclusive Athletic Departments as Agents of Social Change
}

\author{
George B. Cunningham \\ Texas A\&M University
}

\begin{abstract}
Despite advances, prejudice against lesbian, gay, bisexual, and transgender (LGBT) individuals continues to plague many areas of sport, including intercollegiate athletics. There are, however, some athletic departments that are inclusive of LGBT athletes, coaches, and administrators, and that have inclusive organizational cultures and practices. In this paper, the author draws from an institutional theory perspective to suggest these athletic departments act as agents of social change, working to deinstitutionalize norms of exclusivity and heterosexism, articulating a viable alternative, and then working to reinstitutionalize new structures, processes, and norms of LGBT diversity and inclusion.
\end{abstract}

Keywords: LGBT, social change, advocacy

Organizations within a given field are more likely to resemble one another than they are to differ (Washington \& Patterson, 2011). This is true for their structure, strategy, technologies, and, of particular importance to the current paper, organizational practices related to diversity and inclusion. This is certainly the case in intercollegiate athletics, where White, able-bodied, heterosexual men have long been the primary power holders (Fink, Pastore, \& Riemer, 2001). As with others who hold positions of privilege, these individuals are reticent to relinquish their position of power, and thus, have worked to establish and maintain systems ensuring this structure. Consider the following data supporting this position: athletic departments largely follow the same diversity management strategy, irrespective of their size and resources (Fink et al., 2001, 2003); women, racial minorities, sexual minorities, the poor, and persons with disabilities are all underrepresented as sport participants and in leadership roles within sport organizations (Cunningham, in press-b); resource allocations across sport contexts reinforce the position of the "haves" (e.g., men's revenue sports) and "have not's" (e.g., all other sports; Mahony et al., 2010); and historical trends couple with idealized notions of amateurism to perpetuate a system that handsomely rewards coaches and administrators for their efforts while withholding such compensation from athletes- the persons responsible for producing the product generating the revenues (Hawkins, 
2013). Various institutionalized forces - including those that are mimetic, normative, and coercive in nature (DiMaggio \& Powell, 1983; see also Cunningham, 2008) - help perpetuate these practices, reinforce their legitimacy, and make them highly resistant to change.

The change-averse nature of sport makes those cases of social transformation all the more important and noteworthy. Various individuals and groups have worked to question the status quo, alter existing systems that perpetuate inequality, offer viable alternatives for new organizational forms, and transform some sport contexts into spaces marked by justice and equality. In some cases, individuals, such as Pat Griffin, Harry Edwards, Richard Lapchick, Ed O'Bannon, Billie Jean King, and Eli Wolff, among others, have championed change and mobilized others to join their efforts. In other cases, secondary stakeholder groups, such as Athlete Ally, the Women's Sports Foundation, and the United Nations, among others, have strongly advocated and pursued social change efforts. These activities have resulted in sport becoming more inclusive and diverse.

A common theme in the aforementioned anecdotal evidence, as well as the scholarship in this area, is a focus on individuals (Powell, 2008; Russell, Muraco, Subramaniam, \& Laub, 2009; Wolf \& Zuckerman, 2012) and advocacy groups (Grenier, 2010; Hensmans, 2003; Rao, Morrill, \& Zald, 2000). Such an emphasis is warranted and serves as a reflection of the social change movements that have taken place in sport and larger society as a whole. Largely missing from this discussion, though, is examination of other organizations within the particular organizational field. I argue here that, just as individuals and external groups advocate for change, so too do some organizations that are situated within a given institutional environment. In this case, these organizations reject the isomorphic pressures to adopt a prevailing organizational archetype and instead embrace alternative organizational forms, values, and practices that model diversity and inclusiveness. In doing so, they demonstrate a viable alternative for other entities within their organizational field, ultimately serving as change agents.

Building from this general thesis, I outline the rest of the paper as follows. First, I situate my arguments around lesbian, gay, bisexual, and transgender (LGBT) inclusiveness within intercollegiate athletics; thus, I first offer an overview of the prevalence of heterosexism and sexual prejudice within that setting and then offer evidence of outliers, or athletic departments that are diverse and LGBT inclusive in nature. In the following section, I draw from social movement literature to illustrate how social change efforts can deinstitutionalize dominant practices of injustice and exclusion. In the final section, I integrate this literature to demonstrate how LGBT inclusive athletic departments act as agents of change, a process that will ultimately lead to a more inclusive intercollegiate athletics environment.

\section{LGBT Inclusiveness in Intercollegiate Sport}

While progress has been made (Anderson, 2009, Griffin, 2012), many athletic departments are still characterized by cultures of heterosexism and individual expressions of sexual prejudice. In some cases, this is a reflection of the broader environment in which the athletic department is situated. Executive Order 11246 prohibits prejudice against LGBT individuals among US federal contractors, 
but there are no federal laws prohibiting workplace discrimination for all sexual minorities. This leaves the onus to the states and municipalities to establish such workplace protections, and while some regions have established such provisions, they are more of the exception than the rule (see "Gay rights," 2012). The end result is that in much of the United States, it is still legal for athletic departments to not hire someone, treat them differently in the workplace, or terminate their employment based on the employee's sexual orientation or gender identity.

The broader culture of sport and physical activity also reinforce heterosexist principles. LGBT athletes, coaches, and players are routinely cast as "other," face negative stereotypes, and experience status loss within the sport context (Sartore \& Cunningham, 2009b). There is evidence that parents (Cunningham \& Melton, 2012; Sartore \& Cunningham, 2009a), students preparing to enter the sport field (Gill, Morrow, Collins, Lucey, \& Schultz, 2006), and current employees (Sartore \& Cunningham, 2010) endorse these perspectives. Sexual minority athletes, coaches, and administrators are negatively affected by this system. Illustrative of these effects, Krane and Barber (2005) conducted a qualitative study with lesbians coaching intercollegiate athletic teams. They found the coaches had negative experiences in their athletic departments and within the coaching profession as a whole. One coach commented, "the coaching world is not always a kind world.... It's a really strange issue within coaching... There are so many lesbians in coaching, and yet it's not somewhere that people can people comfortable with that being known about them" (p. 257). Coaching is not the only context where sexual minorities feel compelled to compartmentalize their sexual orientation, as gay men working in professional sport organizations have also expressed similar sentiments (Cavalier, 2011).

Because of these and other dynamics, it is rare for athletic departments to have sexual orientation diversity - that is, a mix of heterosexual, lesbian, gay, and bisexual persons - among its coaches and administrators. I observed as much in a study of NCAA athletics departments, as almost one in five departments reported no sexual orientation diversity (Cunningham, 2010). Fink and her colleagues (2001, 2003) have also observed that most athletic departments follow diversity management strategies that call for minimal compliance with diversity-related mandates and lack in inclusiveness.

Together, this literature supports the notion that sexual prejudice and heterosexism are commonplace in many intercollegiate athletics settings. The values, norms, and systems perpetuating heterosexism and sexual prejudice have been legitimated and reinforced over time, resulting in them largely being institutionalized within the sport context (Cunningham, 2012). And, because highly institutionalized environments are generally change averse, transformation of intercollegiate athletics into a more diverse, inclusive environment requires social change among individuals, secondary stakeholder groups, and-particularly germane to this paper-athletic departments within the specific organizational field. I outline the mechanism through which this can occur in the following section.

\section{Institutional Perspectives on Social Change}

In this paper, I draw from den Hond and de Bakker's (2007) theoretical framework to develop the argument that athletic departments can be agents of change. While 
they concentrated on secondary stakeholder groups and their role in social change, as I outline in the following section, the theory is applicable to this discussion. den Hond and de Bakker focused on ideologies and how they separated different types of activist groups, where an ideology represents, "an interconnected set of beliefs and attitudes relating to problematic aspects of social and political topics that are shared and used by members of a group and that inform and justify choice behavior" (p. 903). In some cases, a group's ideology is such that the members believe target organizations are part of the problem so can in no way be part of the solution; den Hond and de Bakker refer to these as radical activist groups. In other cases, group members believe that while target organizations are the root problem of the focal issue, these same organizations can also be part of the solution in transforming the current state; these are referred to as reformative activist groups.

den Hond and de Bakker (2007) then suggest that radical and reformative activist groups will engage in various behaviors aimed at deinstitutionalizing organizational practices and structures. This is primarily done by questioning the moral legitimacy of the activities taking place. Reformative groups focus on what are called consequential arguments, or the effects of the offending organization's activities on the welfare of society. Radical groups will employ consequential arguments, but will also buttress these with structural arguments, which question the very legitimacy of the offending organization as an appropriate entity. To illustrate, let us consider the issue of student athlete welfare. Reformative activist groups are thought to focus on consequential arguments, such as noting how current practices in athletic departments (e.g., requiring too much practice time) are harmful to the academic and physical welfare of the athletes. Radical activist group are thought to draw from these arguments and also buttress them by questioning the degree to which athletic departments should exist at all.

Once the moral legitimacy of organizational practices are questioned, activist groups must then engage in theoretization, or the process that "specifies why the potential adopter should attend to the behavior of one population and not some other, what effects the practice will have, and why the practice is particularly applicable or needed" (Strang \& Meyer, 1993, p. 500). During this process, the activist groups articulate an effective alternative to the current goals, practices, and structures prevalent within a given institutional field. den Hond and de Bakker (2007) suggest arguments relying solely on the moral legitimacy are unlikely to provide the needed impetus for change, so additional rationales must be offered in the form of pragmatic legitimacy. In this case, activist groups offer a rationale for a viable alternative, pointing to how such changes would benefit all involved. This might include attracting new clients, improving one's reputation, or developing better decision making capabilities. To illustrate, let us return to the student athlete welfare example, where from a pragmatic legitimacy perspective, activist groups might argue that improved treatment of student athletes might result in better athlete morale, the attraction of talented athletes to the university, and a positive reputation. Finally, as reformative activist groups see target organizations as a part of the solution, they are more likely than their radical counterparts to employ pragmatic legitimacy techniques.

Finally, once the viable alternative has been articulated, activist groups work to ensure reinstitutionalization takes place (den Hond \& de Bakker, 2007). This is the process where new organizational forms and practices become legitimated and engrained (see also Washington \& Patterson, 2011; Kikulus, 2000). This is where 
reformative activist groups will spend considerable energies, working with proactive organizations to ensure the alternative organizational forms are cemented. At this stage in the process, they will also leave the laggards behind or directly challenge them, as these organizations are resistant to and unwilling to pursue the necessary changes. The authors note:

By challenging laggard firms to raise their minimum level of corporate social change activities, the average standard in the entire organizational field will be lifted. By stimulating proactive firms in their corporate social change policies and practices to become more proactive, reformative groups may try to expand the frontiers of corporate social change policies and practices in the organizational field. (pp. 916-917)

Radical activist groups adopt a different approach. They are unlikely spend as much energy in this phase, as they fear being co-opted by the very organizations of whom they are critical. In fact, rather than working with proactive firms, they are likely to challenge them.

\section{LGBT Focused Social Change in Intercollegiate Athletics}

In this paper, I draw from den Hond and de Bakker's (2007) theory to suggest that LGBT inclusive athletic departments can, and frequently do, serve as agents for social change - activities that will ultimately make intercollegiate athletics a more diverse, inclusive environment. As I proceed, it is necessary to highlight two foundational positions.

First, den Hond and de Bakker's work focuses on secondary stakeholder groups advocating for change, and this is consistent with much of the institutional theory focused work on social movements (see Bies, Bartunek, Fort, \& Zald, 2007). But, LGBT inclusive athletic departments are within a particular organizational field, not external to it. I suggest that because of a variety of societal, organizational, and individual level factors (see Cunningham, in press-a), these entities have rejected isomorphic pressures to adopt dominant structures, processes, and strategies. Instead, the legitimacy of their organizational forms comes from the sexual orientation and gender identity diversity of their athletics and staff, as well as the inclusiveness of their organizational culture. As a result, this puts LGBT inclusive athletic departments in a distinctive position: as a member of a particular organizational field, the athletic department are advocating for change among their peers, highlighting the folly of their peers' current practices and offering evidence of a new alternative; yet, even though they are within that organizational field, they have different organizational forms than do their peers, uniquely positioning themselves as agents for social change.

Second, because they are members of the field, they are likely to adopt a reformative position. According to den Hond and de Bakker (2007), social change groups adopting a reformative position are likely to perceive offending organizations as the source of the problem but also a participant in creating the solution. This ideological stance differs from that of a radical social change agent, where change agents do not believe offending organizations can take part in creating the needed 
transformations. The notion that athletics will not be delivered through athletic departments housed in larger universities is not feasible for reformists; thus, the offending athletic departments must be part of the change process for athletics to be more inclusive. Given this reality, a reformative ideological stance-and the subsequent tactics involved with such a position — are likely most feasible for LGBT inclusive athletic departments.

Third, as members of a particular organizational field, LGBT inclusive athletic departments will likely seek field level change. LGBT inclusive athletic departments have already changed from prevailing institutional forms and practices, so engaging in organizational transformations are unnecessary. Instead, they pursue field level changes - fundamental transformations to the way athletics operates and the level of inclusiveness within that domain-not simply the operations and activities of a single, offending athletic department. To do so, I suggest they follow the three major steps outlined in den Hond and de Bakker's (2007) framework: engage in efforts to deinstitutionalize noninclusive practices, articulate a viable alternative, and work to reinstitutionalize new forms (see Figure 1).

\section{Deinstitutionalization of Non-Inclusive Practices}

As a first step, I argue LGBT inclusive athletic departments engage in various practices to question the moral legitimacy of noninclusive practices. Consistent

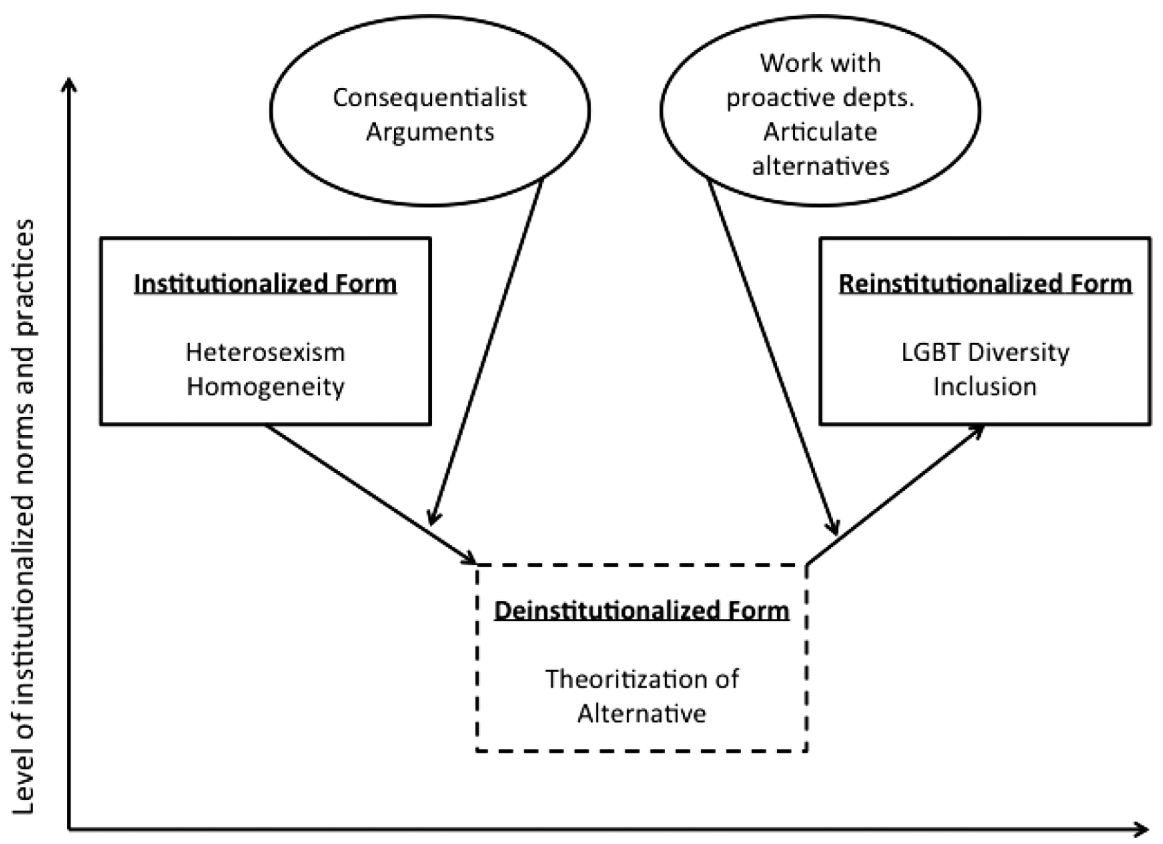

Time spent engaging in social change efforts

Figure 1 - Social Change Mechanisms for LGBT Inclusive Athletic Departments. 
with den Hond and de Bakker (2007), these athletic departments, having adopted a reformative ideological position, are likely to form consequential arguments. Our research in various athletic departments suggests these arguments take several forms.

First, our research suggests coaches and administrators in inclusive athletic departments see inclusion as an integral part of the departmental culture (Cunningham, in press-a; Singer \& Cunningham, 2012). It is enmeshed into the fabric of the operations, structures, strategies, mission, and personnel decisions. Inclusion is part of the department's ethos and seen as a moral obligation. The systemic integration of diversity and inclusion into all elements of the department's activities also separates it from others that proclaim to embrace diversity but do not deeply embed principles of inclusion (Cunningham, 2009b; Shaw, 2007).

This mindset is important, as it informs diversity-related attitudes and behaviors. For instance, in making consequential arguments aimed at deinstitutionalization, LGBT inclusive athletic departments might suggest that exclusive athletic departments are breaking their social contracts with key internal and external stakeholders; further, just as inclusive athletic departments sense a moral obligation for such practices, they might develop similar arguments to persuade their counterparts to engage in change activities.

Second, I have found evidence that leaders in inclusive departments actively promote principles of diversity and inclusion in national and international settings (Cunningham, in press-a). In one instance, an athletic director at a women's college was active in speaking at state, national, and international conferences about gender equity and sexual orientation diversity. This made an impression on the coaches and administrators in her department, as they knew the value she placed on inclusion. Importantly, though, she also sought to deinstitutionalize norms of exclusion, homogeneity, and heterosexism. The athletic director spoke of challenging people's assumptions, seeking to break down their taken-for-granted attitudes. In the same study, I observed similar behaviors among coaches at another university. In this case, they promoted a "You can Play" campaign among other coaches in their league. The purpose of this campaign was to promote the idea that irrespective of one's sexual orientation, it is the skill that matters on the court, field, or ice. Just as with the aforementioned athletic director, this coach's actions helped to challenge the status quo of heterosexism and sexual prejudice in his sport.

\section{Theoretization of a Viable Alternative}

Following efforts to deinstitutionalize organizational practices, change agents must engage in the theoretization process (den Hond \& de Bakker, 2007), or the process whereby new, viable forms are presented. Moral legitimacy is likely to be a part of this argument, particularly because it was central in the deinstitutionalization arguments. But, resting solely on such positions is unlikely to be effective; rather, offending organizations will also need to know how changes will benefit them and their key stakeholders. As Fink and Pastore (1999) note, "while it would be wonderful for all of those in positions of power to realize the moral and social advantages of diversity, it may not be a realistic goal. Thus, for diversity initiatives to be truly embedded within the organization, those in power must be convinced of diversity's relationship to organizational effectiveness" (p. 314). Therefore, the theoretization of a viable alternative should also include pragmatic legitimacy (den Hond \& de Bakker, 2007), 
and as outlined below, there is considerable evidence suggesting LGBT inclusive entities have process and effectiveness gains beyond their competitors.

Inclusiveness and Improved Performance. Florida is a geography who studies the reasons why some geographic regions prosper while others do not. In articulating creative capital theory (Florida, 2012), he suggested that creative people are the key to generating economic gains, and further, creative people are attracted to places with high concentrations of technology, highly educated people, and inclusiveness. With respect to the latter element, he argues LGBT inclusiveness is likely the best indicator, as communities that are inclusive of sexual minorities are also likely to be inclusive of people across a host of other diversity dimensions. I applied the theory's primary tenets to the athletic department context, seeking to understand if sexual orientation diversity, when coupled with an inclusive work environment, impacted the creative work environment (Cunningham, 2011a). Using data collected from a sample of NCAA Division III athletic departments, I found this was indeed the case. Specifically, the most creative work environments existed in departments where sexual orientation diversity and inclusiveness were high.

An LGBT inclusive workplace is likely to positively affect other dynamics internal to the workplace. For instance, in a collective case study of two inclusive athletic departments, I found that LGBT diversity and inclusiveness served as a source of learning for department employees, allowed coaches to serve as role models for sexual minority athletes, afforded department employees to celebrate diversity, and allowed employees to freely express personal identities important to them (Cunningham, in press-a). Speaking to the importance of identity expression, one coach commented: "The word that comes to mind is 'authenticity.' I think it just allows people to be really authentic and therefore bring that to work and their conversations with each other. I think it is really valuable." These important processes should improve the group dynamics in the work environment, ultimately leading to more successful organizations.

LGBT inclusiveness might also help positive attitudes among external stakeholders. For example, Melton and I developed a theoretical framework whereby we argued that customers might be positively inclined toward LGBT inclusive sport organizations because of the goodwill associated with being socially responsible (Cunningham \& Melton, 2011). This is consistent with the notion that there is a moral obligation for diversity and inclusion in the work environment (Cunningham \& Fink, 2006), and external stakeholders reward organizations for realizing this commitment. Melton and I have observed as much in an experimental study, as would-be job applicants were attracted to LGBT inclusive sport organizations (Melton \& Cunningham, 2012). Furthermore, consumers believe LGBT inclusive fitness clubs value diversity along a host of domains, something that contributes to their intentions to join the club (Cunningham \& Melton, 2014). While the latter two examples were set outside the intercollegiate athletics context, they do support the notion that people external to the organization are attune to how inclusive it is toward LGBT individuals, and they base their attitudes and behaviors accordingly.

These data suggest LGBT inclusiveness is associated with improved processes and external stakeholder evaluations, both of which should result in enhanced organizational effectiveness. This is, indeed, the case. In a study of Division I athletic 
departments, I observed that racial diversity interacted with the presence of an inclusive work environment to predict objective measures of performance (Cunningham, 2009a). Two years later, I examined a similar question but with a focus on sexual orientation diversity (Cunningham, 2011b). The same pattern emerged, as LGBT diversity, when coupled with an inclusive workplace environment, resulted in high performance. Diverse, inclusive organizations far outperformed their peers, with a sevenfold increase observed in some situations.

This evidence offers a compelling pragmatic alternative to the prevailing institutional practices of exclusion and homogeneity. Inclusive practices benefit sexual minority athletes, coaches, and administrators; they are consistent with social and moral expectations for inclusion; they allow for effective internal group processes; and they result in the athletic departments far outperforming their peers in objective measures of performance.

Process for Creating Inclusive Work Environments. In addition to articulating the benefits of sexual orientation diversity and inclusion, it is also necessary to effectively convey how athletic departments can create and maintain inclusive work environments. My recent work in this area sheds some light on these processes (Cunningham, in press-a). In a collective case study, I collected data via artifacts, news articles, and interviews from two athletic departments noted for their diverse and inclusive environment. In addition to asking the participants about the benefits of inclusion, I was keenly interested in understanding how they created and maintained a culture of diversity and inclusion.

Consistent with Ferdman's (2014) theory, I observed factors from multiple levels of analysis influenced this process. At the individual level, coaches and administrators engaged in difficult dialogues with each other and had opportunities for intergroup contact. Noting the importance of these activities, one coach noted: "I think it is easy for someone to say, 'I hate gays,' or, 'I don't understand gays,' or to make derogatory remarks and be discriminating.... When you start having a relationship, even if its purely professional, with someone who is openly gay, I think it just really forces you to look inside and perhaps change some perceptions."

Leaders also make a difference in reinforcing and shaping a LGBT inclusive culture (Cunningham, in press-a). They do so through their advocacy on the topic and by setting expectations for inclusion in the department. Strong leadership has a trickle down effect (Ruiz, Ruiz, \& Martínez, 2011), as people take note of leader expectations and modeling, and behave accordingly. This is particularly the case when it comes to the deinstitutionalization of organizational practices, systems, and values (Parish, 2005). Thus, leaders who model the efficacy of LGBT inclusiveness are likely to positively impact their own work environments, as well as others within the organizational field.

Organizational level activities also influence the inclusiveness of the workplace (Cunningham, in press-a). This comes in the form of education and programming, such as diversity training for student athletes, faculty, and staff. Inclusive practices also shape the workplace culture. For example, inclusive organizations have partner benefits and partner placement programs. They are also sure to include partnersas opposed to "guests" or only spouses - in departmental events. In departmental directories, partners can be listed as well. All of these activities set the tone and expectations for diversity and inclusion in the work environment. 


\section{Reinstitutionalization}

Finally, reinstitutionalization, or the process whereby newly adopted norms, practices, and values are institutionalized, represents the last stage in the change process (den Hond \& de Bakker, 2007). In the case of the current paper, LGBT diversity and inclusiveness - something that was once the exception-might now become expected and commonplace within athletics, similar to what Anderson $(2009,2011)$ has primarily observed in settings outside the US. Consistent with den Hond and de Bakker (2007), I argue that inclusive athletic departments will spend consider energies in this stage of the change process. They will do so in several ways.

First, while arguments made in the deinstitutionalization process were geared at noncompliant athletic departments, during the reinstitutionalization phase, inclusive athletic departments will partner with other proactive organizations to ensure the change is solidified (see also den Hond \& de Bakker, 2007). If laggards are not on board after the articulation of consequential arguments and pragmatic alternatives, they are unlikely to be convinced with additional persuasive efforts. Thus, inclusive athletic departments are likely to partner with other, similarly-minded entities to ensure the change takes place and is well-grounded. Such an approach is needed when inclusive athletic departments are seeking to endeavor in field level change. In this case, the formative actions must include other departments within that field-though these departments were once part of the problem, they can now be part of the solution, too.

Second, inclusive athletic departments are likely to spend considerable energies articulating the viable alternatives to their less-inclusive counterparts can pursue. This means leaders will engage in meaningful, sometimes difficult discussions with external constituents (Cunningham, in press-a), highlighting the various ways in which LGBT diversity and inclusiveness can benefit the athletes, coaches, administrators, and department as a whole. This might take place at coaching conventions, through events on campus, or through informal conversations, among others. They are also likely to demonstrate how others have also benefited from shifting to a more inclusive mindset. Such efforts are likely to be particularly persuasive given the benefits of vicarious achievement (Bandura, 2001) and mimetic pressures influencing the legitimacy of organizational practices (DiMaggio \& Powell, 1983; Washington \& Patterson, 2011).

\section{Conclusions}

Given the highly institutionalized nature of intercollegiate sport, creating field-level change is a difficult undertaking. Of the transformations that do take place, individuals within the sport context (e.g., Billie Jean King, Harry Edwards) or outside, secondary stakeholder groups (e.g., Athlete Ally, Women's Sports Foundation) represent the entities most likely to engage in advocacy efforts. Consistent with this pattern, most of the social change scholarship focuses on individual agents (Powell, 2008; Russell et al., 2009; Wolf \& Zuckerman, 2012) or social change groups external to the organizational field (Grenier, 2010; Hensmans, 2003; Rao et al., 2000). It is also possible, though, for organizations within a particular organizational field to seek and advocate for social change. In this way, organizations might seek to change the field in which they operate, creating a more just and 
socially responsible context. In this paper, I drew from work in institutional theory (den Hond \& de Bakker, 2007) and in LGBT equality to argue that LGBT inclusive athletic departments can and do act as social change agents. They highlight the folly of exclusionary practices, actively model the benefits of diversity and inclusion, and offer pragmatic alternatives for other athletic departments to adopt. In doing so, they work to make intercollegiate sport a more inclusive, diverse context.

I should note that there are elements of the model that are more evidence-based than others. This is also reflected in the verb tense used to articulate the model. For instance, I drew from my work and that of other scholars to offer evidence of the efforts among LGBT inclusive athletic departments to deinstitutionalize exclusionary practices and norms. There are also some signals of inclusive athletic departments engaging in the theoritization process, articulating pragmatic options for others to follow. These change efforts are taking place, and with shifts in policies to make athletics more inclusive (see, for example, Buzuvis, 2012; Griffin, 2012), inclusive policies and practices are starting to take hold. However, a field level shift in the inclusiveness of athletic department policies, practices and norms has yet to occur; as such, efforts to deeply embed and reinstitutionalize inclusive practices are also on the horizon. Thus, the reinstitutioanlization theorizing is more anticipatory in nature.

That noted, I do expect the need for reinstitutionalization will be realized sooner than later. While much of intercollegiate sport is marked by heterosexism and sexual prejudice, particularly within the Southern US, marked shifts have occurred elsewhere (e.g., Anderson, 2011; Griffin, 2012). As this field level change crystalizes, LGBT inclusive athletic departments will continue to work with other proactive entities to deeply embed principles of LGBT diversity and inclusion, leaving the laggards behind. The laggards will likely then be confronted with a straight-forward option: adopt more LGBT inclusive policies, practices, norms and thrive; or, hold on to the archaic, prejudice-laden ones currently in place, hurting coaches, players, and administrators, and languishing behind others in important organizational processes and outcomes. LGBT inclusive athletic departments have already made their choice, and they are actively working with others to ensure this important social change does take place.

\section{References}

Anderson, E. (2009). Inclusive masculinity: The changing nature of masculinities. New York: Routledge.

Anderson, E. (2011). Masculinities and sexualities in sport and physical cultures: Three decades of evolving research. Journal of Homosexuality, 58, 565-578. PubMed doi:1 $0.1080 / 00918369.2011 .563652$

Bandura, A. (2001). Social cognitive theory: An agentic perspective. Annual Review of Psychology, 52, 1-26. PubMed doi:10.1146/annurev.psych.52.1.1

Bies, R.J., Bartunek, J.M., Fort, T.L., \& Zald, M.N. (2007). Corporations as social change agents: Individual, interpersonal, institutional, and environmental dynamics. Academy of Management Review, 32, 788-793. doi:10.5465/AMR.2007.25275515

Buzuvis, E. (2012). Including transgender athletes in sex-segregated sport. In G.B. Cunningham (Ed.), Sexual orientation and gender identity in sport: Essays from activists, coaches, and scholars (pp. 23-34). College Station, TX: Center for Sport Management Research and Education. 
Cavalier, E.S. (2011). Men at sport: Gay men's experiences in the sport workplace. Journal of Homosexuality, 58, 626-646. PubMed doi:10.1080/00918369.2011.563662

Cunningham, G.B. (2008). Creating and sustaining gender diversity in sport organizations. Sex Roles, 58, 136-145. doi:10.1007/s11199-007-9312-3

Cunningham, G.B. (2009a). The moderating effect of diversity strategy on the relationship between racial diversity and organizational performance. Journal of Applied Social Psychology, 36, 1445-1460. doi:10.1111/j.1559-1816.2009.00490.x

Cunningham, G.B. (2009b). Understanding the diversity-related change process: A field study. Journal of Sport Management, 23, 407-428.

Cunningham, G. B. (2010). Predictors of sexual orientation diversity in intercollegiate athletics. Journal of Intercollegiate Sport, 3, 256-269

Cunningham, G.B. (2011a). Creative work environments in sport organizations: The influence of sexual orientation diversity and commitment to diversity. Journal of Homosexuality, 58, 1041-1057. PubMed doi:10.1080/00918369.2011.598413

Cunningham, G.B. (2011b). The LGBT advantage: Examining the relationship among sexual orientation diversity, diversity strategy, and performance. Sport Management Review, 14, 453-461. doi:10.1016/j.smr.2010.11.003

Cunningham, G.B. (2012). A multilevel model for understanding the experiences of LGBT sport individuals. Journal for the Study of Sports and Athletes in Education, 6, 5-20. doi:10.1179/ssa.2012.6.1.5

Cunningham, G.B. (in press).-a). Creating and sustaining workplace cultures supportive of LGBT employees in college athletics. Journal of Sport Management.

Cunningham, G. B. (in press-b). Diversity and inclusion in sport organizations ( $3^{\text {rd }} \mathrm{ed}$.). Scottsdale, AZ: Holcomb-Hathaway.

Cunningham, G.B., \& Fink, J.S. (2006). Diversity issues in sport and leisure: Introduction to a special issue. Journal of Sport Management, 20, 455-465.

Cunningham, G.B., \& Melton, E.N. (2011). The benefits of sexual orientation diversity in sport organizations. Journal of Homosexuality, 58, 647-663. PubMed doi:10.1080/0 0918369.2011 .563664

Cunningham, G.B., \& Melton, E.N. (2012). Prejudice against LGB coaches: The influence of race, religious fundamentalism, modern sexism, and contact with sexual minorities. Sociology of Sport Journal, 29, 283-305.

Cunningham, G.B., \& Melton, E.N. (2014). Signals and cues: LGBT inclusive advertising and consumer attraction. Sport Marketing Quarterly, 23, 37-46.

den Hond, F., \& de Bakker, F.G. (2007). Ideologically motivated activism: How activist groups influence corporate social change activities. Academy of Management Review, 32, 901-924. doi:10.5465/AMR.2007.25275682

DiMaggio, P.J., \& Powell, W.W. (1983). The iron cage revisited: Institutional isomorphism and collective rationality in organizational fields. American Sociological Review, 48, 147-160. doi:10.2307/2095101

Ferdman, B.M. (2014). The practice of inclusion in diverse organizations: Toward a systemic and inclusive framework. In B.M. Ferdman \& B.R. Deane (Eds.), Diversity at work: The practice of inclusion (pp. 3-54). San Francisco, CA: Jossey-Bass.

Fink, J.S., \& Pastore, D.L. (1999). Diversity in sport? Utilizing the business literature to devise a comprehensive framework of diversity initiatives. Quest, 51, 310-327. doi:1 0.1080/00336297.1999.10491688

Fink, J.S., Pastore, D.L., \& Riemer, H.A. (2001). Do differences make a difference? Managing diversity in Division IA intercollegiate athletics. Journal of Sport Management, 15, 10-50.

Fink, J.S., Pastore, D.L., \& Riemer, H.A. (2003). Managing employee diversity: Perceived practices and organizational outcomes in NCAA Division III athletic departments. Sport Management Review, 6, 147-168. doi:10.1016/S1441-3523(03)70057-6

Florida, R. (2012). The rise of the creative class, revisited. New York, NY: Basic Books. 
Gay rights in the US, state by state. (2012, May 8). The Guardian. Retrieved online from: http://www.theguardian.com/world/interactive/2012/may/08/gay-rights-united-states.

Gill, D.L., Morrow, R.G., Collins, K.E., Lucey, A.B., \& Schultz, A.M. (2006). Attitudes and sexual prejudice in sport and physical activity. Journal of Sport Management, 20, 554-564.

Grenier, R.S. (2010). Moments of discomfort and conflict: Holocaust museums as agents of change. Advances in Developing Human Resources, 12, 573-586. doi:10.1177/1523422310394434

Griffin, P. (2012). LGBT equality in sports: Celebrating our successes and facing our challenges. In G.B. Cunningham (Ed.), Sexual orientation and gender identity in sport: Essays from activists, coaches, and scholars (pp. 1-12). College Station, Texas: Center for Sport Management Research and Education.

Hawkins, B. (2013). The new plantation: Black athletes, college sports, and predominantly White NCAA institutions. New York, NY: Palgrave Macmillan.

Hensmans, M. (2003). Social movement organizations: A metaphor for strategic actors institutional fields. Organization Studies, 23, 355-381. doi:10.1177/0170840603024003908

Kikulis, L.M. (2000). Continuity and change in governance and decision making in national sport organizations: Institutional explanations. Journal of Sport Management, 14, 293-320.

Krane, V., \& Barber, H. (2005). Identity tensions in lesbian intercollegiate coaches. Research Quarterly for Exercise and Sport, 76, 67-81.

Mahony, D.F., Hums, M.A., Andrew, D.P., \& Dittmore, S.W. (2010). Organizational justice in sport. Sport Management Review, 13, 91-105. doi:10.1016/j.smr.2009.10.002

Melton, E.N., \& Cunningham, G.B. (2012). The effect of LGBT-inclusive policies, gender, and social dominance orientation on organizational attraction. International Journal of Sport Management, 13, 444-462.

Parish, S.L. (2005). Deinstitutionalization in two states: The impact of advocacy, policy, and other social forces on services for people with developmental disabilities. Research and Practice for Persons with Severe Disabilities, 30, 219-231. doi:10.2511/rpsd.30.4.219

Powell, S. (2008). Souled out? How Blacks are winning and losing in sports. Champaign, IL: Human Kinetics.

Rao, H., Morrill, C., \& Zald, M.N. (2000). Power plays: How social movements and collective action create new organizational forms. Research in Organizational Behavior, 22, 237-281. doi:10.1016/S0191-3085(00)22007-8

Ruiz, P., Ruiz, C., \& Martínez, R. (2011). Improving the "leader-follower" relationship: Top manager or supervisor? The ethical leadership trickle-down effect on follower job response. Journal of Business Ethics, 99, 587-608. doi:10.1007/s10551-010-0670-3

Russell, S.T., Muraco, A., Subramaniam, A., \& Laub, C. (2009). Youth empowerment and high school gay-straight alliances. Journal of Youth and Adolescence, 38, 891-903. PubMed doi:10.1007/s10964-008-9382-8

Sartore, M.L., \& Cunningham, G.B. (2009a). Sexual prejudice, participatory decisions, and panoptic control: Implications for sexual minorities in sport. Sex Roles, 60, 100-113. doi:10.1007/s11199-008-9502-7

Sartore, M.L., \& Cunningham, G.B. (2009b). The effects of the lesbian label in the sport context: Implications for women of all sexual orientations. Quest, 61, 289-305. doi:1 $0.1080 / 00336297.2009 .10483617$

Sartore, M.L., \& Cunningham, G.B. (2010). The lesbian label as a component of women's stigmatization in sport organizations: A comparison of two health and kinesiology departments. Journal of Sport Management, 24, 481-501.

Shaw, S. (2007). Touching the intangible? An analysis of The Equality Standard: A Framework for Sport. Equal Opportunities International, 26, 420-434. doi:10.1108/02610150710756630 
Singer, J.N., \& Cunningham, G.B. (2012). A case study of the diversity culture of an American university athletic department: Implications for educational stakeholders. Sport Education and Society, 17, 647-669. doi:10.1080/13573322.2011.552572

Strang, D., \& Meyer, J.W. (1993). Institutional conditions for diffusion. Theory and Society, 22, 487-511. doi:10.1007/BF00993595

Washington, M., \& Patterson, K.D. (2011). Hostile takeover or joint venture: Connections between institutional theory and sport management research. Sport Management Review, 14, 1-12. doi:10.1016/j.smr.2010.06.003

Wolf, B., \& Zuckerman, P. (2012). Deviant heroes: Nonconformists as gents of justice and social change. Deviant Behavior, 33, 639-654. doi:10.1080/01639625.2011.647587 